\title{
Hydrogen Peroxide Electrosynthesis Using Recycled Graphite Granules as 3D Cathode. Comparison with Other Commercial Materials and Optimization Studies
}

\author{
ANA-DOMNICA MARINCEAN ${ }^{1}$, SORIN-AUREL DORNEANU ${ }^{1,2 *}$, PETRU ILEA ${ }^{1,2 *}$ \\ ${ }^{1}$ Babes-Bolyai University, Faculty of Chemistry and Chemical Engineering, 11 Arany Janos Str., 400028 Cluj-Napoca, \\ Romania \\ ${ }^{2}$ Babes-Bolyai University, Interdisciplinary Research Institute on Bio-Nano-Sciences, 42 Treboniu Laurian Str., 400271, \\ Cluj-Napoca, Romania
}

\begin{abstract}
This study aims to evaluate the ability of the graphite granules $(G G)$ recycled from spent $\mathrm{Zn}$ $C$ batteries to act as $3 D$ cathode for hydrogen peroxide (HP) electrosynthesis (HPE) in eco-friendly conditions (unbuffered $0.05 \mathrm{M} \mathrm{Na}_{2} \mathrm{SO}_{4}$ solution, air as $\mathrm{O}_{2}$ source). The performances of GG were compared to those of other usual carbonaceous cathode materials for HPE such as graphite bloc, graphite felt and reticulate vitreous carbon $(R V C)$, using a divided filter-press electrochemical reactor. The operational parameters such as the polarization mode, electrolyte and air flow rates, applied potentials or imposed currents, and aeration mode were optimized by $1 \mathrm{~h}$ tests of electrosynthesized HP accumulation (EHPA). Considering as optimization criteria the best compromise between the final HP concentration, global current efficiency and electrical energy specific consumption, we find that the most efficient material for EHPA was RVC of 500 ppi, exploited in galvanostatic mode and using an original aeration system. In optimized conditions, for the GG cathode, very promising efficiency indicators were evaluated, suggesting that better results can be obtained by electrode geometry optimization and GG pretreatment.
\end{abstract}

Keywords: hydrogen peroxide electrosynthesis, divided filter-press reactor, carbonaceous materials, $3 D$ electrodes, recycled graphite granules

\section{Introduction}

Hydrogen peroxide (HP) is an environmentally friendly reagent used in the chemical industry and environment protection. HP, as source of powerful oxidant hydroxyl radical $(\bullet \mathrm{OH})$, is a key factor for the chemical [1-3] and electrochemical advances oxidation processes (EAOPs) [4] proposed for waste [5] and drinking waters [6, 7] treatment. Among the EAOPs, the electro-Fenton process (EFP), based on the in-situ HP electrosynthesis (HPE) by the oxygen reduction reaction (ORR) and generation of the - $\mathrm{OH}$ in the presence of $\mathrm{Fe}^{2+}$, represents a promising perspective for the treatment of waste waters [8]. Because the EFP success strongly depends on HPE efficiency, significant efforts have been made to optimize the operational parameters [9-12]. Also, the cathodic material essentially influences the HPE, the carbonaceous materials being preferred due to their high catalytic activity for ORR, chemical resistance and low catalytic activity for side reactions [12]. Consequently, carbonaceous materials such as graphite bloc (GB), [11, 13], graphite felt (GF) [6, 7, 11, 14], reticulated vitreous carbon (RVC) [11, $15,16]$, unmodified [16] or activated [17, 18] carbon fibers, boron doped diamond [13] and glassy carbon pellets [19] were tested as cathodes for HPE. In order to increase the HPE efficiency, different physical [20-22], chemical [21, 23-26] or electrochemical [27] methods were tested to modify the surface of the raw carbonaceous materials.

\footnotetext{
*email:dorneanu@chem.ubbcluj.ro; pilea@chem.ubbcluj.ro
} 
Because the low oxygen solubility is one of the major HPE efficiency limitations, different oxygenation methods such as the use of the gas diffusion electrodes $[9,28,29]$, air or pure $\mathrm{O}_{2}$ sparging in the cathode compartment [11, 17], catholyte tank [16, 26, 30-33] or catholyte flow [22], air injection trough GF electrode [34], use of atmospheric [35-37] or pressurized jet aerators [38] and in-situ oxygen generation $[10,39]$, were proposed.

In this context, we performed comparative HPE optimization tests in eco-friendly conditions using recycled graphite granules (GG) from spent $\mathrm{Zn}-\mathrm{C}$ batteries and other conventional unmodified carbonaceous materials (GB, GF and RVC).

\section{Experimental part}

Experimental techniques, setups and equipments

During the present work, for each tested cathodic material and the corresponding filter-press electrochemical reactor (FPER) configuration, two experimental techniques were used. Firstly, in order to establish the starting conditions for the optimization studies, preliminary measurements were performed by hydrodynamic linear voltammetry (HLV) with the simultaneous on-line monitoring of the electrosynthesized HP concentration. Subsequent, $1 \mathrm{~h}$ tests of electrosynthesized hydrogen peroxide accumulation (EHPA) were completed in potentiostatic or galvanostatic mode for several combinations of the operational parameters.

The experimental setups used for the present studies, described schematically in Figure 1, included, as main constituent, a modified Microflow Cell ${ }^{\circledR}$ FPER (ElectoCell A/S, Denmark) equipped with Nafion 117 (DuPont, USA) cation exchanges membranes (C.E.M.) and polytetrafluoroethylene (PTFE) tube (O.D. $=1.6 \mathrm{~mm}$, I.D. $=1 \mathrm{~mm})$ Luggin capillaries for the electrodes potential measurement. In order to prevent the interruption of the references liquid junctions by air bubbles, the PTFE Luggin capillaries were permanently flushed during the all experiments with anolyte and catholyte, at a flow rate of 1 $\mathrm{mL} / \mathrm{min}$, using the two sections (P2.1 and P2.2) of the peristaltic pump (PP) P2 of Reglo Digital MS2/8 type (ISMATEC, Switzerland).

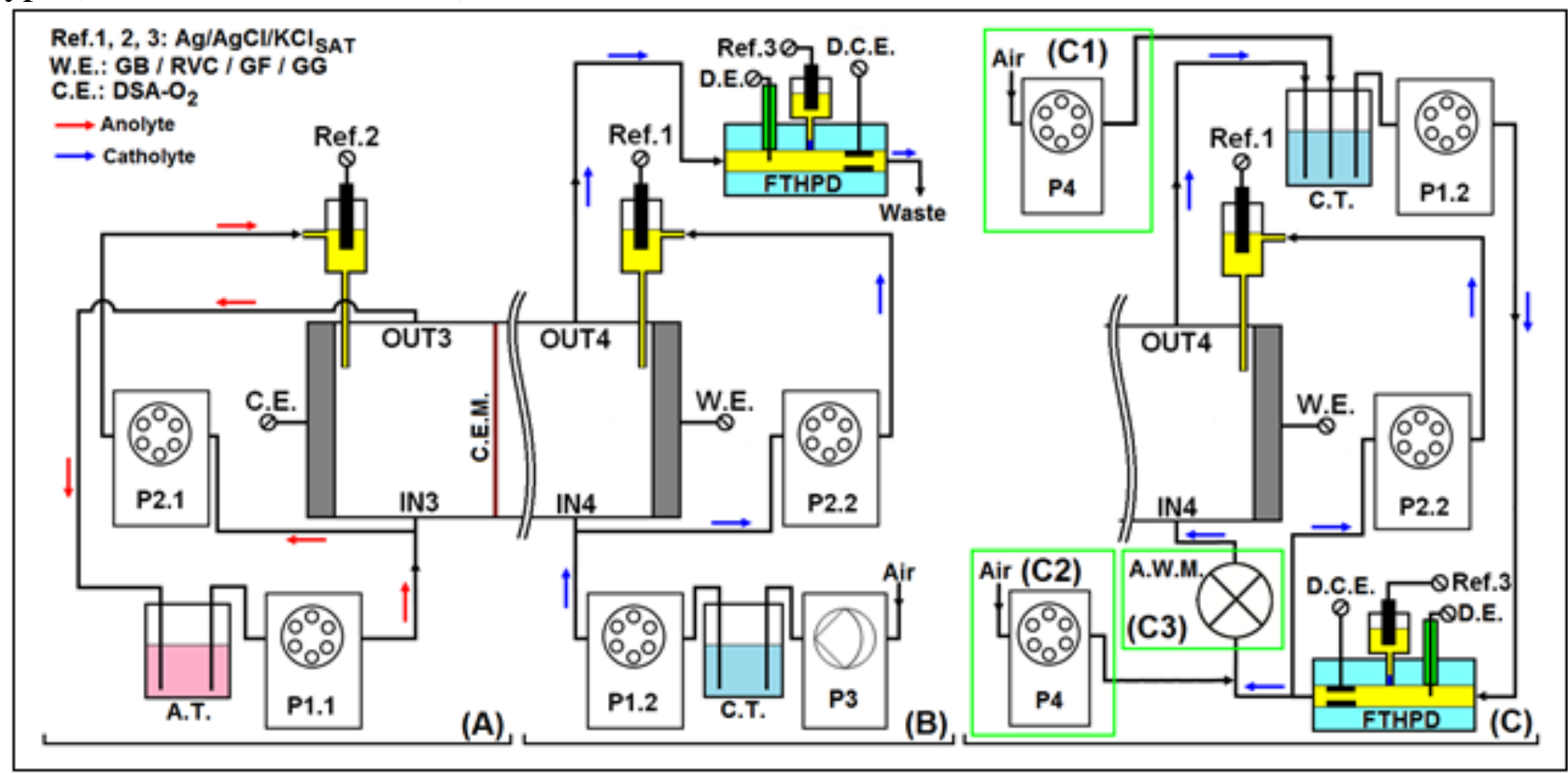

Figure 1. Schematic of the experimental setups: (A) Anodic circuit for all measurements; (B) Cathodic circuit for HLV studies; (C) Cathodic circuits for EHPA tests: (C1) Air injected in the catholyte tank; (C2) Air injected in the catholyte flow; (C3) Supplementary Air-Water Mixer (A.W.M.). 
For both HLV and EHPA measurements, as indicated in figure 1.A, the anodic section of the experimental setups was quasi-identical, including the anodic part of the FPER equipped with 1 or 2 counter-electrodes (C.E.) of $10 \mathrm{~cm}^{2}$ active areas, a glass anolyte tank (A.T.) of $200 \mathrm{~mL}$ and one section (P1.1) of the P1 PP. The C.E. and P1 PP were of DSA- $\mathrm{O}_{2}\left(\mathrm{Ti} / \mathrm{IrO}_{2}-\mathrm{Ta}_{2} \mathrm{O}_{5}\right.$ from ElectoCell A/S, Denmark) and Reglo Analog MS2/8 (ISMATEC, Switzerland) type, respectively.

The cathodic section of the experimental setup for HLV measurements has included, as indicated in fig. 1.B, the cathodic part of the FPER equipped with different models of working electrodes (W.E.) made from carbonaceous materials, a polypropylene catholyte tank (C.T.) of 5 L, the second section (P1.2) of the P1 PP and an original flow-through hydrogen peroxide detector (FTHPD) [40] connected at the output of the FPER cathodic compartment (OUT4). Additionally, in order to saturate the catholyte with air, a membrane pump (P3) and a porous PTFE dispenser immersed in the C.T., were used.

For EHPA studies, as indicated in Figure 1.C, the cathodic section of the experimental setups included the cathodic compartment of the FPER equipped with the carbonaceous cathodes, a glass C.T. of $200 \mathrm{~mL}$ and the FTHPD inserted between the P1.2 section of the P1 PP and the input of the FPER cathodic compartment (IN4). Concerning the air feed during the EHPA tests, three different solutions were tested. As indicated in the section (C1) of Figure 1.C, in a first embodiment, the air was pumped, at a flow rate controlled by the PP P4 (also of Reglo Digital MS2/8 type), directly in the C.T. In a second embodiment (see section (C2) from Figure 1.C), the air was pumped with P4 and injected in the catholyte flow before the entrance in the FPER cathodic compartment (input IN4). Finally, in a third embodiment, the sections $\mathrm{C} 2$ and $\mathrm{C} 3$ were used together, the last one acting as a supplementary Air-Water Mixer (A.W.M.). For this purpose, a PTFE body centrifugal pump of MD-10 model (IWAKI CO., LTD, Japan) was used, assuring an intensified air dispersion in the catholyte flow.

Concerning the cathode construction, as described in figure 2, five different carbonaceous materials and corresponding FPER configurations were tested. For the first two embodiments (Figure 2.A and 2.B), commercially available GB and RVC 100 ppi (pores per inch) electrodes, both of $5 \mathrm{~mm}$ thickness (ElectoCell A/S, Denmark) were used. For the third and fourth configuration (figure 2.C and 2.D), a rectangular piece of RVC 500 ppi $\left(33 \times 30 \times 8 \mathrm{~mm}^{3}\right)$ and a $6 \mathrm{~mm}$ thickness GF layer of $0.082 \mathrm{~g} / \mathrm{cm}^{3}$ (both from Alfa Aesar), respectively, were fixed in corresponding polymethylmethacrylate (PMM) spacers. In the last embodiment, described in Figure 2.E, recycled GG were used as 3D cathode for HPE. In this purpose, the cylindrical graphite current collectors were carefully extracted from 10 Toshiba AA spent $\mathrm{Zn}-\mathrm{C}$ batteries, washed consecutively with $48 \% \mathrm{H}_{2} \mathrm{SO}_{4}, 48 \% \mathrm{H}_{2} \mathrm{SO}_{4}+5 \%$ oxalic acid and doubledistilled water. Subsequently, the recycled graphite rods were air dried, crushed using a pair of pliers and classified by sieving. Finally, the new 3D cathode was made by fixing a $3 \mathrm{~mm}$ th home madeickness layer of GG, having the diameter between 0.65 and $2 \mathrm{~mm}$, over a $3 \mathrm{~mm}$ thickness layer of GF and a GB electrode. For all tested carbonaceous materials, the W.E. exposed geometrical areas were of $10 \mathrm{~cm}^{2}$.

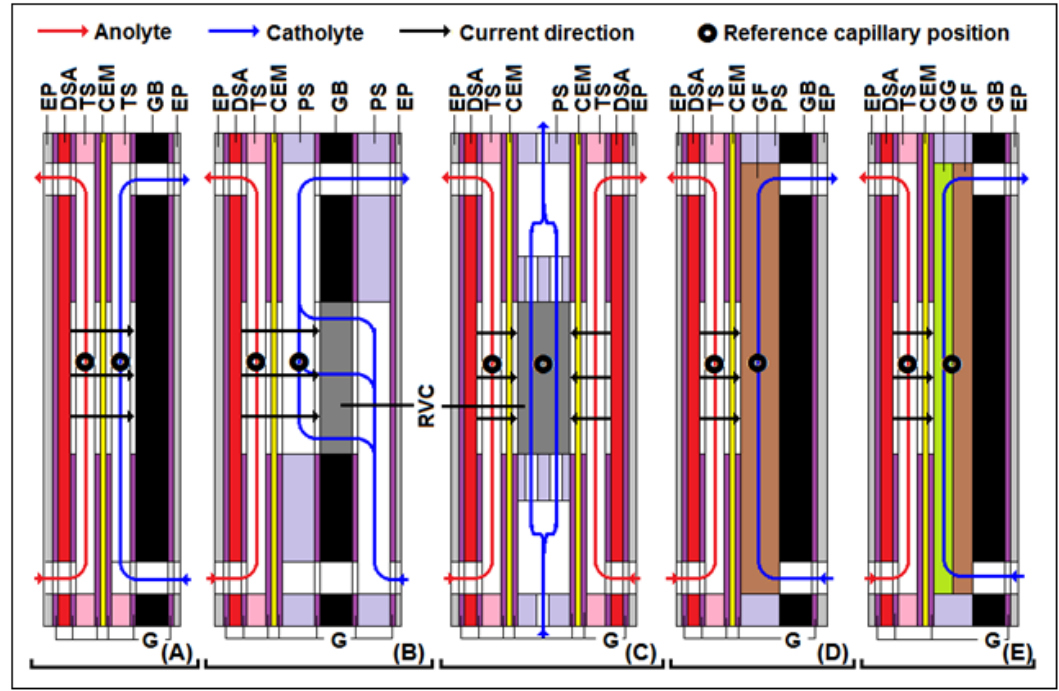

Rev. Chim., 71 (3), 2020, 102-116
104
Figure 2. Configurations of the FPER based on different cathodic materials: A) GB; B) RVC 100 ppi; C) RVC 500 ppi; D) GF; E) Recycled GG. Others components:

CEM - cation exchanges membranes, DSA - dimension stable anode, EP - PTFE (Teflon ${ }^{\circledR}$ ) end plate, $\mathrm{G}$ - rubber gaskets, TS -

Teflon ${ }^{\circledR}$ spacers, PS - PMM spacers 
For all the measurements, the reference electrodes $($ Ref. $1 \div 3)$ were of $\mathrm{Ag} / \mathrm{AgCl} / \mathrm{KCl}$ sAT type $(\mathrm{E}=$ $+0.197 \mathrm{~V}$ vs. SHE), all mentioned potentials being reported to these electrodes. Also, the FPER electrodes (W.E., C.E., Ref.1 and Ref.2) were connected to a DXC236 computer controlled potentiostat (Datronix Computers, Romania) while the FTHPD electrodes (Ref.3, D.E. - detector electrode and D.C.E. - detector counter-electrode) were connected to a home made computer-controlled low-current potentiostat. For the experiments control and data acquisition, dedicated software applications elaborated using the LabView 2015 environment (National Instruments, USA) were used.

\section{Materials and methods}

All the measurements were carried out in an unbuffered, low ionic strength solutions $\left(0.05 \mathrm{M} \mathrm{Na}_{2} \mathrm{SO}_{4}\right)$ used as anolyte and catholyte solutions, prepared from solid $\mathrm{Na}_{2} \mathrm{SO}_{4} 10 \mathrm{H} 2 \mathrm{O}$ (Sigma-Aldrich, p.a. grade) and double-distilled water, with an intrinsic $p \mathrm{H}$ of $\sim 4.2$. After the EHPA experiments, the final HP concentration $\left(\left[\mathrm{H}_{2} \mathrm{O}_{2}\right]_{F}\right)$ was evaluated by titration with $0.1 \mathrm{~N} \mathrm{KMnO}_{4}$ standard solution. $\mathrm{A} 48 \% \mathrm{H}_{2} \mathrm{SO}_{4}$ solution was used to acidify the catholyte samples before titrations and to clean the recycled graphite rods.

Experimental procedures

Before each set of HLV experiments, the A.T. and C.T. were filled with $100 \mathrm{~mL}$ and $5 \mathrm{~L}$ of fresh $0.05 \mathrm{M} \mathrm{Na}_{2} \mathrm{SO}_{4}$ solutions, respectively. Subsequently, all the setup hydraulic elements were filled with electrolyte and the catholyte was saturated with air for $30 \mathrm{~min}$. Finally, the measurements were performed, for each tested cathodic material, at equal anolyte and catholyte flow rates $\left(Q_{e l}\right)$ of $4,8,20$ and $40 \mathrm{~mL} / \mathrm{min}$ and a scan rate $(v)$ of $5 \mathrm{mV} / \mathrm{s}$.

For the EHPA studies, the A.T. and C.T. were filled with $100 \mathrm{~mL}$ samples of fresh catholyte and anolyte, all the setup hydraulic elements were filled with electrolyte and the measurements were carried out for $1 \mathrm{~h}$.

For an increased accuracy of the HP concentration electrochemical monitoring, before each VLH or EHPA experiment, the D.E. from the FTHPD was conditioned $(45,25$ and $35 \mathrm{~s}$ at $-0.9 \mathrm{~V},+1.0$ and +0.7 $\mathrm{V} v s$. Ref.3, respectively) at $Q_{e l}$ of $20 \mathrm{~mL} / \mathrm{min}$. After the conditioning pre-treatment, during all the VLH or EHPA tests, the D.E. was maintained connected and polarized at the last applied D.E. potential $\left(E_{D . E}\right)$ value (+0.7 V vs. Ref.3). All the experiments (conditioning, HLV and EHPA) were performed at the room temperature $\left(\sim 25^{\circ} \mathrm{C}\right)$.

\section{Results and discussions}

\section{A. Measurements by HLV}

As pointed before, the main goal of the HLV measurements was to identify the starting experimental parameters for the optimization studies. Practically, the influences of the $Q_{e l}$ and applied W.E. potential $\left(E_{\text {W.E. }}\right)$ on the HPE rates were evaluated for all tested cathodic materials. Because the instant HP concentration $\left(\left[\mathrm{H}_{2} \mathrm{O}_{2}\right]_{t}\right)$ evaluated with the FTHPD strongly depends on the $Q_{e l}$ (due to the dilution factor), for a more relevant comparison, the recorded D.E. currents $\left(I_{D . E}\right.$.) were converted to instant generation rates (I.G.R.) values using the calibration data [40] (evaluated at different $Q_{e l}$ ), the corresponding $Q_{e l}$ values and the following equation:

$$
\text { I.G.R. }=I_{D . E .} \cdot K \cdot Q_{e l}=\left[\mathrm{H}_{2} \mathrm{O}_{2}\right]_{t} \cdot Q_{e l}(\mu \mathrm{g} / \mathrm{min})
$$

where $K$ represents the calibration constant corresponding to the $Q_{e l}$ value. Based on this treatment, in Figure 3 is presented an example concerning the influence of the $E_{W . E}$. on the $I_{W . E}$ and I.G.R. values recorded by HLV on RVC 100 ppi at different $Q_{e l}$ values. 


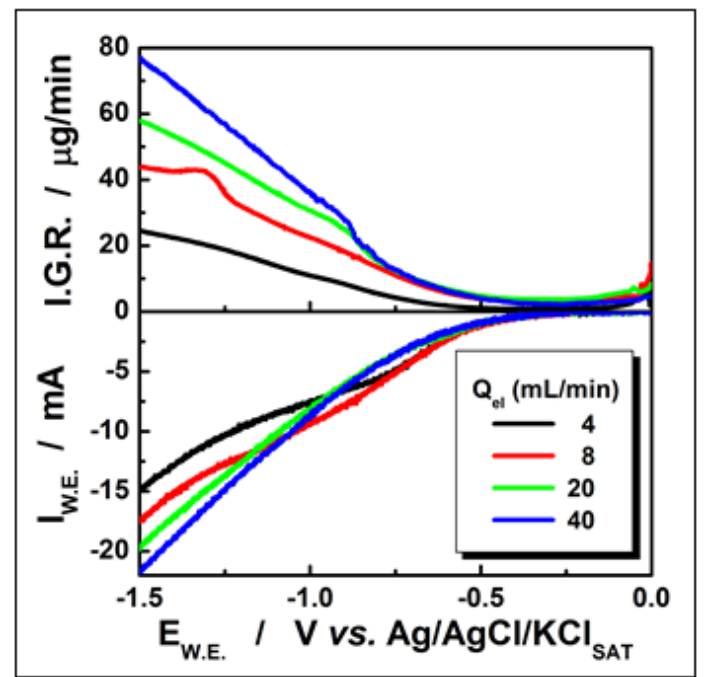

Figure 3. Example of the applied $E_{W . E}$. influence on the $I_{\text {W.E. }}$ and I.G.R. recorded by HLV on RVC 100 ppi cathode at different flow rates, $v=5 \mathrm{mV} / \mathrm{s}$

As it can be seen from Figure 3, for RVC 100 ppi cathode, the highest I.G.R. values were obtained for the maximum $Q_{e l}$ value $(40 \mathrm{~mL} / \mathrm{min})$ and an $E_{W . E}$. value around $-1.0 \mathrm{~V}$ vs. Ref.1. Because similar dependencies were obtained for all the other tested cathodic materials (results not shown), we decide to use, for all further optimization studies, a $Q_{e l}$ value of $40 \mathrm{~mL} / \mathrm{min}$. Based on data comparison presented in Figure 4, we conclude that, for GB, RVC 100 ppi, RVC 500 ppi, GF and GG electrodes, the appropriate $E_{\text {W.E. }}$ and $I_{W . E \text {. }}$ values for starting the optimization tests correspond to -0.7, -1.0, -0.8, - 0.75 and $-1.0 \mathrm{~V} v s$. Ref. 1 or $-2,-10,-15,-40$ and $-40 \mathrm{~mA}$, respectively.

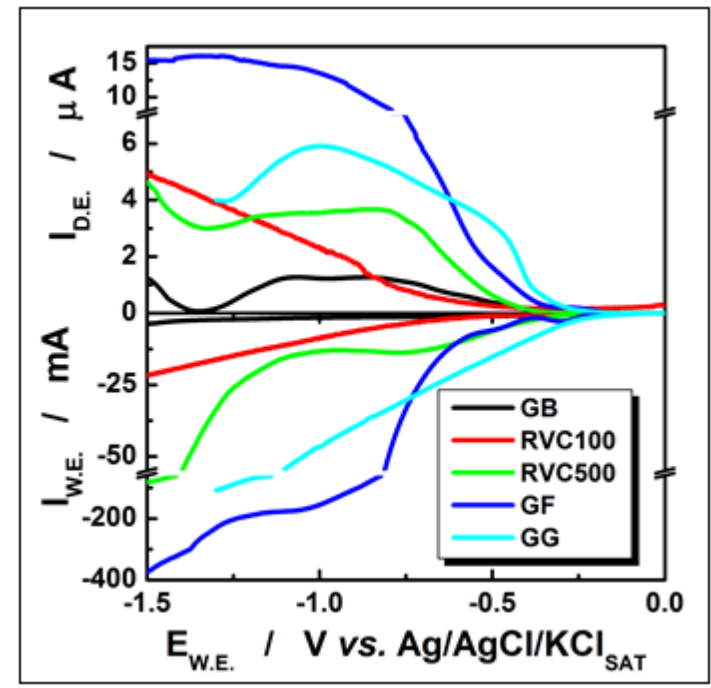

Figure 4. Comparison between the $I_{W . E .}$ and $I_{D . E}$. evolutions recorded by HLV on all tested cathodic materials at $Q_{e l}$ of 40 $\mathrm{mL} / \mathrm{min}$ and $v=5 \mathrm{mV} / \mathrm{s}$

The results presented in Figure 4 also suggest that, for identical W.E. exposed geometrical areas of $10 \mathrm{~cm}^{2}$ and $Q_{e l}$ of $40 \mathrm{~mL} / \mathrm{min}$, at the above mentioned optimal $E_{W . E}$. values, the obtained I.G.R. increased in the next order: GB < RVC 100 ppi $<$ RVC 500 ppi $<$ GG $<$ GF.

\section{B. Measurements by EHPA}

B.1. Treatment of EHPA data

In a first approach, for all tested materials, the more efficient conditions for EHPA were considered as the optimal compromise between the $\left[\mathrm{H}_{2} \mathrm{O}_{2}\right]_{F}$, global current efficiency $(C$.Ef.G) and global electrical energy specific consumption $\left(W_{S . G}\right)$. $\left[\mathrm{H}_{2} \mathrm{O}_{2}\right]_{F}$ was evaluated, for each experiment, by titration with 0.1 
$\mathrm{N} \mathrm{KMnO}_{4}$, and used to calculate the practical mass $\left(m_{P}\right)$ of the accumulated HP. C.Ef.G was evaluated as:

$$
C . E f ._{G}=\frac{m_{P}}{m_{T}} \cdot 100=\frac{m_{P} \cdot z \cdot F}{M_{H P} \int_{O}^{t_{F}} I_{W . E .} \cdot d t} \cdot 100 \quad(\%)
$$

where $m_{T}, z, F, M_{H P}$ and $t_{F}$ represent the theoretical mass of the accumulated HP, number of transferred electrons ( 2 in this case), Faraday constant (96485 As/mol), HP molar mass and final experiment time, respectively, the other terms being defined before.

Considering $E_{T}$ the voltage at the FPER terminals, $W_{S . G}$ was evaluated as:

$$
W_{S . G}=\frac{\int_{0}^{t_{F}} E_{T} \cdot I_{W . E .} \cdot d t}{m_{P} \cdot 3.6}(\mathrm{kWh} / \mathrm{kg})
$$

Unfortunately, the $I_{D . E}$. evolutions during all experiments reveals that the HP accumulation rate do not remains constant, recording a significant decrease toward the experiment ends. Consequently, for a more accurate evaluation of the EHPA process efficiency evolution, the intermediate values for HP concentration $\left(\left[\mathrm{H}_{2} \mathrm{O}_{2}\right]_{I}\right)$, current efficiency $\left(C . E f_{. I}\right)$ and electrical energy specific consumption $\left(W_{S . I}\right)$ were also evaluated using dedicated LabView applications. Practically, the recorded data were divided, according eq. (4), in equal duration segments, $\Delta t$, of $180 \mathrm{~s}$, and, for each data segment, the intermediate HP mass variation, $\Delta m_{I}$, was calculated using eq. (5):

$$
\begin{gathered}
\Delta t=t(i)-t(i-1) \quad(s) \\
\Delta m_{I}=\left(\left[\mathrm{H}_{2} \mathrm{O}_{2}\right]_{t(i)}-\left[\mathrm{H}_{2} \mathrm{O}_{2}\right]_{t(i-1)}\right) \cdot V_{C A T} \quad(g)
\end{gathered}
$$

where $t(i), t(i-1),\left[\mathrm{H}_{2} \mathrm{O}_{2}\right]_{t(i)}$ and $\left[\mathrm{H}_{2} \mathrm{O}_{2}\right]_{t(i-1)}$ represent the time and the HP concentrations at the end and beginning of each data segment, respectively, and $V_{C A T}$ is the catholyte volume.

For each data segment, the values of C.Ef.I, $W_{S . I}$ and $\left[\mathrm{H}_{2} \mathrm{O}_{2}\right]_{I}$, were calculated as:

$$
\begin{aligned}
& C . E f \cdot{ }_{I}=\frac{\Delta m_{I} \cdot z \cdot F}{M_{H P} \int_{t(i-1)}^{t(i)} I_{W . E .} \cdot d t} \cdot 100 \quad(\%) \\
& W_{S . I}=\frac{\int_{t(i-1)}^{t(i)} E_{T} \cdot I_{W . E .} \cdot d t}{\Delta m_{I} \cdot 3.6}(\mathrm{kWh} / \mathrm{kg}) \\
& {\left[\mathrm{H}_{2} \mathrm{O}_{2}\right]_{I}=\left(\left[\mathrm{H}_{2} \mathrm{O}_{2}\right]_{t(i)}-\left[\mathrm{H}_{2} \mathrm{O}_{2}\right]_{t(i-1)}\right) / 2 \quad(\mathrm{ppm})}
\end{aligned}
$$

where the $\left[\mathrm{H}_{2} \mathrm{O}_{2}\right]_{t}$ was calculated using the $\left[\mathrm{H}_{2} \mathrm{O}_{2}\right]_{F}$ value and considering that the recorded $I_{D . E \text {. }}$ is directly proportional (linear correlation) to the HP concentration.

\section{B.2. Preliminary optimization studies in potentiostatic mode}

For the first optimization studies in potentiostatic mode, we decided to use as cathode the commercially available RVC electrode. As presented in Figure 2.B, it consisted in a rectangular piece $\left(33 \times 30 \times 5 \mathrm{~mm}^{3}\right)$ of 100 ppi RVC fixed with graphite doped conductive epoxy in a $5 \mathrm{~mm}$ thickness GB, allowing, theoretically, an electrolyte flow parallel with the current lines. Based on the literature suggestions [30-33], the catholyte oxygenation was made by air sparging in the C.T. according to the experimental setup described in Figure 1.C(C1). Firstly, for the $Q_{\text {air }}$ influence study, the $E_{W . E}$. was fixed, based on the HLV results, at $-1.0 \mathrm{~V} v$ s. Ref.1. The results concerning the influence of $Q_{a i r}$ and $E_{W . E}$ on the intermediate and global efficiency indicators for the EHPA process (EIEHPAP) are presented in fig. 5 and table 1, respectively. 

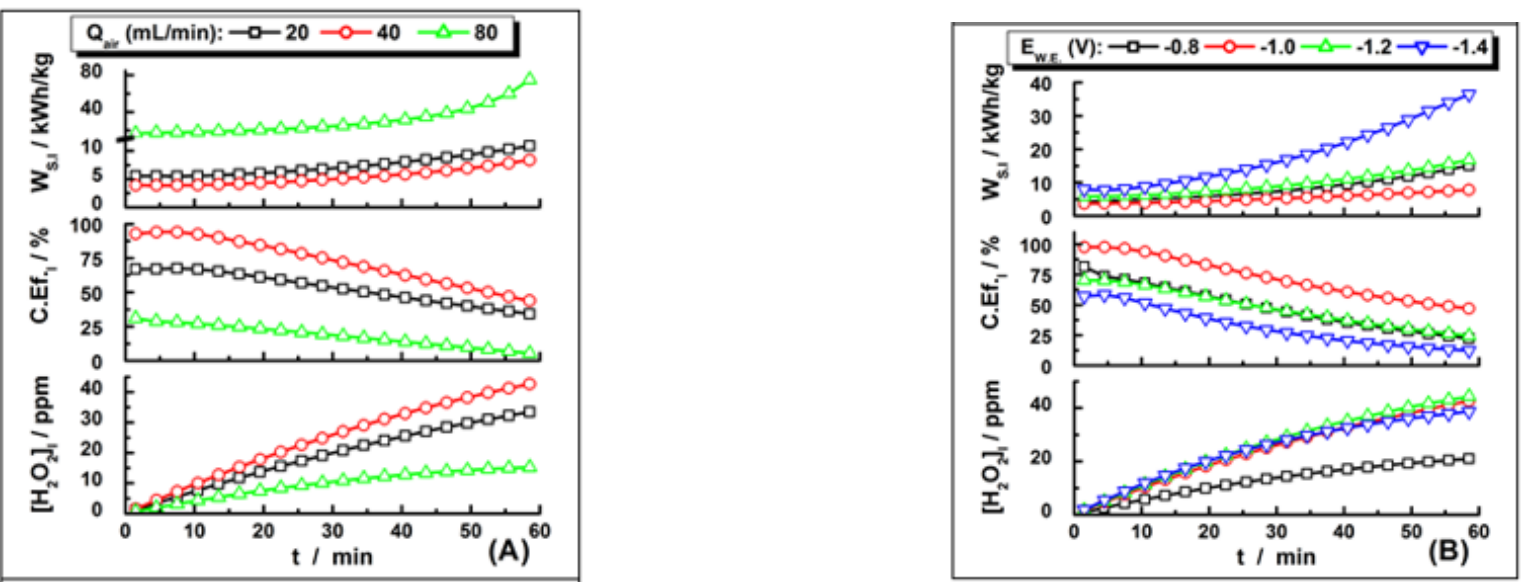

Figure 5. Influence of $Q_{a i r}(\mathrm{~A})$ and $E_{W . E .}$ (B) on $\left[\mathrm{H}_{2} \mathrm{O}_{2}\right]_{I}, C . E F_{\text {.I }}$ and $W_{\text {S.I. }}$ evaluated in potentiostatic mode for the RVC 100 ppi cathode at $Q_{e l}=40 \mathrm{~mL} / \mathrm{min} ; E_{W . E .}=-1.0 \mathrm{~V} \mathrm{vs.} \mathrm{Ref.1(A);} Q_{a i r}=40 \mathrm{~mL} / \mathrm{min}$ (B).

Table 1

Influence of $Q_{a i r}$ and $E_{W . E .}$ on $I_{W . E . M .},\left[\mathrm{H}_{2} \mathrm{O}_{2}\right]_{f}, C . E f . G$ and $W_{S . G .}$ evaluated in potentiostatic mode for the RVC 100 ppi cathode

\begin{tabular}{|c|c|c|c|c|c|}
\hline $\begin{array}{c}Q_{\text {air }} \\
(\mathrm{mL} / \mathrm{min})\end{array}$ & $\begin{array}{l}E_{w \cdot E} \\
\text { (V) }\end{array}$ & $\begin{array}{l}\text { IW.I.M } \\
(\mathrm{mA})\end{array}$ & $\begin{array}{c}{\left[\mathrm{H}_{2} \mathrm{O}_{2}\right]_{\mathrm{F}}} \\
(\mathrm{ppm})\end{array}$ & $\begin{array}{l}\text { C.Ef.G } \\
(\%)\end{array}$ & $\begin{array}{c}W_{\text {S.G }} \\
(\mathrm{kWh} / \mathrm{kg})\end{array}$ \\
\hline \multicolumn{6}{|c|}{ Air Flow Rate influence } \\
\hline 20.0 & \multirow{3}{*}{-1.0} & -10.1 & 34.0 & 52.9 & 7.0 \\
\hline 40.0 & & -9.40 & 43.3 & 72.4 & 5.1 \\
\hline 80.0 & & -13.0 & 15.3 & 18.6 & 20.7 \\
\hline \multicolumn{6}{|c|}{ Electrode Potential influence } \\
\hline \multirow{3}{*}{40.0} & -0.8 & -7.10 & 21.3 & 47.5 & 7.1 \\
\hline & -1.2 & -15.1 & 45.0 & 47.0 & 8.8 \\
\hline & -1.4 & -19.7 & 39.1 & 31.2 & 14.4 \\
\hline
\end{tabular}

As it can be seen from fig. 5.A, for all tested $Q_{a i r}$ values, the evolutions of the $\left[\mathrm{H}_{2} \mathrm{O}_{2}\right]_{I}$ values indicate a permanent decrease of the EHPA rates in respect to the elapsed time. Simultaneously, the value of $C . E F . I$ and $W_{\text {S.I. }}$ decreases and increases, respectively. Considering that the catholyte have a weakly acid character (intrinsic $p \mathrm{H}$ of $\sim 4.2$ ), this behavior can be explained by the fact that, in parallel with the main HPE process:

$$
\mathrm{O}_{2}+2 \mathrm{H}^{+}+2 e^{-} \rightarrow \mathrm{H}_{2} \mathrm{O}_{2}
$$

several competitive (parasitic) processes can occur, such as total (4 electrons) reduction of dissolved $\mathrm{O}_{2}$, $\mathrm{H}_{2}$ evolution and HP electrochemical reduction at the cathode surface or HP bulk disproportionation, described by equations (10) - (13), respectively [11, 16, 34]:

$$
\begin{aligned}
& \mathrm{O}_{2}+4 \mathrm{H}^{+}+4 e^{-} \rightarrow 2 \mathrm{H}_{2} \mathrm{O} \\
& 2 \mathrm{H}^{+}+2 e^{-} \rightarrow \mathrm{H}_{2} \\
& \mathrm{H}_{2} \mathrm{O}_{2}+2 \mathrm{H}^{+}+2 e^{-} \rightarrow 2 \mathrm{H}_{2} \mathrm{O} \\
& 2 \mathrm{H}_{2} \mathrm{O}_{2} \rightarrow \mathrm{O}_{2}+2 \mathrm{H}_{2} \mathrm{O}
\end{aligned}
$$

Moreover, the processes corresponding to the equations (12) and (13) are favored by the increase of the electrosynthesized HP concentration due to the accumulation process, inducing a permanent degradation of the EIEHPAP [11, 16, 34, 37].

From another point of view, by correlating the data from figure 5.A and table 1, it is clear that, in respect to the tested $Q_{\text {air }}$ values, the best EIEHPAP were obtained for air injected in the C.T. at 40 $\mathrm{mL} / \mathrm{min}$, leading to a minimal $I_{\text {W.E. }}$ mean value $\left(I_{\text {W.E.M }}\right)$ of $-9.4 \mathrm{~mA}$. For $Q_{\text {air }}$ of $20 \mathrm{~mL} / \mathrm{min}$, considering 
the poor conductivity of the catholyte and the non-uniform distribution of the applied potential in the volume of the 3D electrode [34,41], the low concentration of the dissolved $\mathrm{O}_{2}$ can induce punctual increases of the cathode overpotential, favoring the competitive processes described by eqs. (10) $\div(12)$ and degrading the EIEHPAP. More interestingly, at $Q_{a i r}=80 \mathrm{~mL} / \mathrm{min}$, even if $I_{\text {W.E.M }}$ reached the maximum value (-13 mA), indicating an efficient catholyte oxygenation and an intense HPE process, the intermediate and global EIEHPAP reached the worst values. This apparently abnormal behavior, signaled also in literature [42, 43], can be explained by the accelerated HP bulk disproportionation and, probably, by the HP stripping due to the excessive air sparging. The last supposition is sustained by the fact that, during the initial tests, the HP accumulation do not occur at all when the intensive aerating system used for the HLV tests (large PTFE diffuser and membrane air pump) was inserted into the C.T. of reduced volume.

Concerning the influence of $E_{\text {W.E. }}$ on the intermediate and global EIEHPAP for the RVC 100 ppi cathode, the obtained results presented in Figure 5.B and the last three rows from table 1, confirmed that the optimal polarization potential corresponds to the value of $-1.0 \mathrm{~V} v s$. Ref.1.

On the other hand, it is important to discuss about the electrolyte velocity, $u_{e l}$, in respect to the electrode, which corresponds to the ratio between $Q_{e l}$ and the flow surface, $S_{F}$ :

$$
u_{e l}=Q_{e l} / S_{F} \quad(\mathrm{~cm} / \mathrm{min})
$$

For the electrolyte flow parallel with the current lines, as in the case of the RVC 100 ppi cathode, the $S_{F}$ corresponds to the electrode exposed geometrical area, leading, for $Q_{e l}=40 \mathrm{~mL} / \mathrm{min}$ and $S_{F}=10 \mathrm{~cm}^{2}$, to an $u_{e l}$ value of $4 \mathrm{~cm} / \mathrm{min}$. Unfortunately, for industrial applications, in order to preserve the same $u_{e l}$ and EIEHPAP values, $Q_{e l}$ and $Q_{a i r}$ must increase proportionally to the electrode surface (e.g. $Q_{e l}=Q_{a i r}$ $=40 \mathrm{~L} / \mathrm{min}$ for $S_{F}=1 \mathrm{~m}^{2}$ ), generating large consumption of electrical energy for pumping. To overcome this drawback, we decided to elaborate and test a new FPER configuration, described in Figure 2.C, that included a new RVC 500 ppi cathode and allowed the electrolyte flow perpendicular to the current lines. For this new arrangement, $S_{F}$ was reduced to $2.4 \mathrm{~cm}^{2}$, determining, for $Q_{e l}=40 \mathrm{~L} / \mathrm{min}$, an $u_{e l}$ value of $16.66 \mathrm{~cm} / \mathrm{min}$. Moreover, taking into account that the use of three-phase system (solid-liquid-gas) seems to be more efficient for HPE [35-38, 44, 45], we decided, as indicated in fig. 1.C(C2), to inject the air directly into the catholyte flow. In the first step, for the $Q_{a i r}$ influence study, the $E_{W . E}$. was fixed (based on the HLV results), at $-0.8 \mathrm{~V} v s$. Ref.1. The results concerning the influence of $Q_{a i r}$ and $E_{W . E}$. on the intermediate and global EIEHPAP for the RVC 500 ppi cathode are presented in fig. 6 and table 2, respectively. Because, in this configuration, two DSA anodes and C.E.M. were used (allowing the exploiting of both RVC lateral surfaces), for an adequate comparison with the RVC 100 ppi cathode, the reported $I_{W . E . M},\left[\mathrm{H}_{2} \mathrm{O}_{2}\right]_{F}$ and $\left[\mathrm{H}_{2} \mathrm{O}_{2}\right]_{I}$ values correspond to half from the real ones.
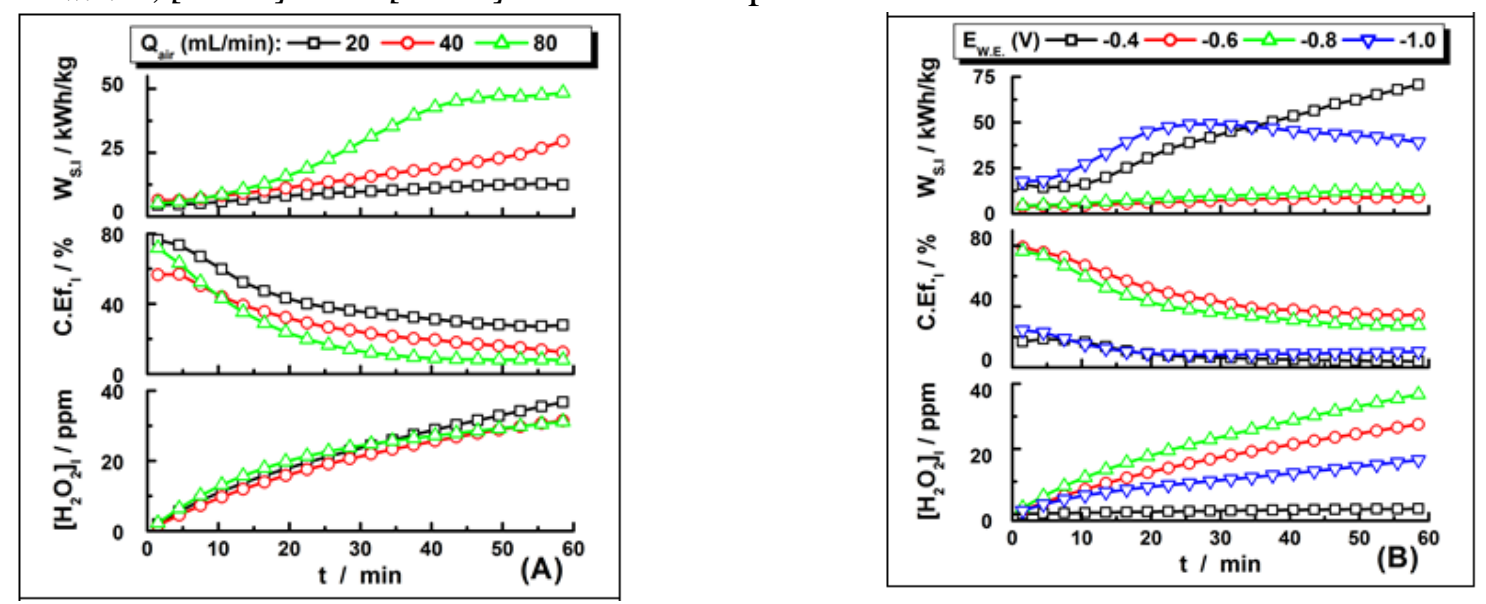

Figure 6. Influence of $Q_{\text {air }}(\mathrm{A})$ and $E_{W . E .}$ (B) on $\left[\mathrm{H}_{2} \mathrm{O}_{2}\right]_{I}, C . E F . I$ and $W_{\text {S.I. }}$ evaluated in potentiostatic mode for the RVC 500 ppi cathode at $Q_{e l}=40 \mathrm{~mL} / \mathrm{min} ; E_{W . E .}=-0.8 \mathrm{~V} v s$. 
Ref.1 (A); $Q_{a i r}=20 \mathrm{~mL} / \mathrm{min}(\mathrm{B})$.

Table 2

Influence of $Q_{a i r}$ and $E_{W . E .}$ on $I_{\text {W.E.M. }},\left[\mathrm{H}_{2} \mathrm{O}_{2}\right]_{F}, C . E F . G$ and $W_{S . G .}$ evaluated in potentiostatic mode for the RVC 500 ppi cathode

\begin{tabular}{|c|c|c|c|c|c|}
\hline $\begin{array}{c}Q_{\text {air }} \\
(\mathrm{mL} / \mathrm{min})\end{array}$ & $\begin{array}{l}\text { Ew.r. } \\
\text { (V) }\end{array}$ & $\begin{array}{l}\text { Iw.E.M } \\
(\mathrm{mA})\end{array}$ & $\begin{array}{c}{\left[\mathrm{H}_{2} \mathrm{O}_{2}\right]_{\mathrm{F}}} \\
(\mathrm{ppm})\end{array}$ & $\begin{array}{l}\text { C.Ef.G } \\
(\%)\end{array}$ & $\begin{array}{c}W_{\mathrm{S} . \mathrm{G}} \\
(\mathrm{kWh} / \mathrm{kg})\end{array}$ \\
\hline \multicolumn{6}{|c|}{ Air Flow Rate influence } \\
\hline 20.0 & \multirow{3}{*}{-0.8} & -14.14 & 40.0 & 44.62 & 7.75 \\
\hline 40.0 & & -18.02 & 31.5 & 27.56 & 13.12 \\
\hline 80.0 & & -23.23 & 23.5 & 19.34 & 19.52 \\
\hline \multicolumn{6}{|c|}{ Electrode Potential influence } \\
\hline \multirow{3}{*}{20.0} & -0.4 & -3.51 & 1.70 & 7.64 & 36.18 \\
\hline & -0.6 & -9.07 & 27.5 & 47.83 & 6.49 \\
\hline & -1.0 & -15.1 & 17.0 & 11.80 & 34.86 \\
\hline
\end{tabular}

By correlating the data from fig. 6 and table 2 we concluded that, for the RVC 500 ppi cathode exploited in potentiostatic mode and oxygen supply by air injection in the catholyte flow, the best EIEHPAP were obtained at $Q_{\text {air }}=20 \mathrm{~mL} / \mathrm{min}$ and $E_{\text {W.E. }}=-0.8 \mathrm{~V} v$ s. Ref.1, leading to a $I_{W . E . M}$ value of around $-14 \mathrm{~mA}$. Comparing these results with those obtained on the RVC 100 ppi cathode in optimized conditions, a small decrease of the $\left[\mathrm{H}_{2} \mathrm{O}_{2}\right]_{F}$ value (from 43.3 to $40.0 \mathrm{ppm}$ ) was observed, while significant degradations of the C.EF.I and $W_{S . I}$ values, of $38 \%$ and $35 \%$, respectively, were recorded. Even if the increased IW.E.M values indicated an intensification of the ORR in the three phase system, the degradation of the EIEHPAP can be explained by the inefficient exploiting of the electrode surface (partial blocking) due to the formation of large air bubbles resulting by the simple air injection in the catholyte flow. Moreover, due to the double-faced configuration of the RVC 500 ppi cathode, the effective $Q_{e l}$ for each half of the electrode diminished to $20 \mathrm{~mL} / \mathrm{min}$, determining, as exemplified in Figure 3, a 25\% decrease in the I.G.R.

From another point of view, it is important to note that the big air bubbles formed inside of the 3D cathode due to the simple air injection in the catholyte flow induces temporally blocking (insulation) of the PTFE reference capillary end, making ineffective the potentiostatic control and determining excessive and uncontrolled polarizations at the W.E. level. This unwanted phenomenon becomes more disturbing in the case of GF and GG tested cathodes, determining the cancelation of the corresponding optimization studies in potentiostatic mode. Only the optimization tests for the GB cathode succeeded, values of $6.7 \mathrm{ppm}, 52.4 \%$ and $4.97 \mathrm{kWh} / \mathrm{kg}$ were obtained for $\left[\mathrm{H}_{2} \mathrm{O}_{2}\right]_{I}, C$.EF.I and $W_{\text {S.I }}$, respectively, at $Q_{\text {air }}=10 \mathrm{~mL} / \mathrm{min}, E_{\text {W.E. }}=-0.7 \mathrm{~V} v s$. Ref. 1 and $I_{\text {W.E.M }}=-1.8 \mathrm{~mA}$.

\section{B.3. Optimization studies in galvanostatic mode}

In order to overcome the drawbacks signaled during the optimization tests in potentiostatic mode, the next experiments were performed in galvanostatic conditions and using an original and improved catholyte aeration system. Practically, as indicated in Figure 1.C(C3), a Teflon® body centrifugal pump was inserted between the point of air injection in the catholyte flow and the input of the FPER cathodic compartment (IN4). This supplementary pump, working at a minimal pressure difference, acts as a efficient air-water mixer that divides the large air injected bubbles in very fine ones and transforms the electrolyte-air mixture in a relative stable emulsion. Moreover, comparing with other intensive aerating arrangements such as the jet-aerators [35-38], our original aerating systems assures an efficient oxygenation with minimal electric energy consumption and without losses of the electrolyte pressure.

Using the new aerating systems, in the first instance, the more promising cathodic materials (RVC 500 ppi and GG) were tested in galvanostatic mode at $\mathrm{Q}_{\mathrm{el}}=40 \mathrm{~mL} / \mathrm{min}$ and using several combinations of $Q_{a i r}$ and $I_{W . E}$. values indicated in table 3. Also, in fig. 7.A and 7.B are exemplified the corresponding 
influences of $Q_{\text {air }}$ and $I_{W . E \text {. }}$ on $\left[\mathrm{H}_{2} \mathrm{O}_{2}\right]_{I}, C$.EF.I and $W_{\text {S.I. }}$ evaluated in galvanostatic mode for the RVC 500 ppi and GG cathodes, respectively.

Table 3

Influence of $Q_{a i r}$ and $I_{W . E .}$ ON $E_{W . E . M},\left[\mathrm{H}_{2} \mathrm{O}_{2}\right]_{F}, C . E f_{. G}$ and $W_{\text {S.G. }}$ evaluated in galvanostatic mode for the RVC 500 ppi and GG cathodes

\begin{tabular}{|c|c|c|c|c|c|}
\hline $\begin{array}{c}Q_{\text {air }} \\
(\mathrm{mL} / \mathrm{min})\end{array}$ & $\begin{array}{l}\text { Iw.r. } \\
(\mathrm{mA})\end{array}$ & $\begin{array}{c}\text { Ew.E.M } \\
\text { (V) }\end{array}$ & $\begin{array}{c}{\left[\mathrm{H}_{2} \mathrm{O}_{2}\right]_{\mathrm{F}}} \\
(\mathrm{ppm})\end{array}$ & $\begin{array}{l}\text { C.Ef.G } \\
(\%)\end{array}$ & $\begin{array}{c}W_{\text {S.G }} \\
(\mathrm{kWh} / \mathrm{kg})\end{array}$ \\
\hline \multicolumn{6}{|c|}{ RVC 500 ppi cathode in galvanostatic mode } \\
\hline 20.0 & -15.0 & -1.69 & 72.7 & 75.90 & 6.66 \\
\hline 20.0 & -12.5 & -1.65 & 60.5 & 75.80 & 7.07 \\
\hline 10.0 & -15.0 & -1.30 & 73.0 & 76.20 & 5.84 \\
\hline 40.0 & -15.0 & -2.00 & 71.3 & 74.39 & 7.39 \\
\hline 80.0 & -15.0 & -1.36 & 63.8 & 71.82 & 6.41 \\
\hline \multicolumn{6}{|c|}{ GG cathode in galvanostatic mode } \\
\hline 20.0 & -40.0 & -0.51 & 37.50 & 14.67 & 27.79 \\
\hline 10.0 & -40.0 & -0.50 & 49.60 & 19.40 & 20.94 \\
\hline 10.0 & -30.0 & -0.44 & 41.30 & 21.54 & 16.76 \\
\hline 10.0 & -20.0 & -0.39 & 41.54 & 32.53 & 10.19 \\
\hline 10.0 & -10.0 & -0.34 & 34.00 & 53.31 & 5.38 \\
\hline
\end{tabular}
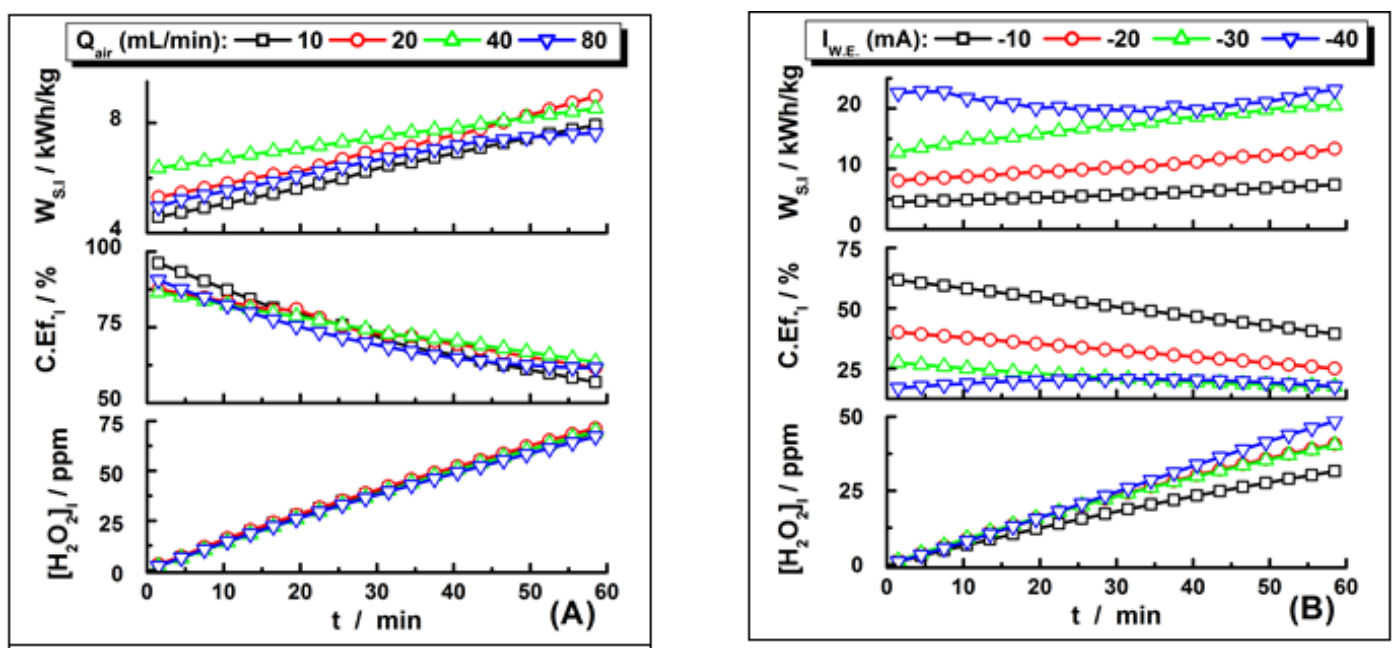

Figure 7. Influence of $Q_{\text {air }}(\mathrm{A})$ and $I_{W . E .}(\mathrm{B})$ on $\left[\mathrm{H}_{2} \mathrm{O}_{2}\right]_{I}, C . E F_{. I}$ and $W_{\text {S.I. }}$ evaluated in galvanostatic mode for the RVC 500 ppi (A) and GG (B) cathode at $Q_{e l}=40 \mathrm{~mL} / \mathrm{min}$; $I_{\text {W.E. }}=-15 \mathrm{~mA}(\mathrm{~A}) ; Q_{\text {air }}=10 \mathrm{~mL} / \mathrm{min}(\mathrm{B})$.

As indicated in the first row of table 3, the optimization study for the RVC 500 ppi cathode exploited in galvanostatic mode was started at operational parameters similar to the best ones evaluated in potentiostatic mode $\left(Q_{\text {air }}=20 \mathrm{~mL} / \mathrm{min}\right.$ and $\left.I_{W . E .}=-15 \mathrm{~mA}\right)$ and revealed a significant improvement of the global EIEHPAP. Because the decrease of the $I_{W . E}$ at $-12.5 \mathrm{~mA}$ (see second row from table 3 ) only reduced the productivity, without the global EIEHPAP enhancement, the optimization tests in respect to $Q_{\text {air }}$ were continued at $I_{W . E .}=-15 \mathrm{~mA}$. By correlating the data from fig. 7.A and table 3 (first 5 rows), we concluded that, for the RVC 500 ppi cathode exploited in galvanostatic mode and using the new aeration system, the best EIEHPAP were obtained at $Q_{\text {air }}=10 \mathrm{~mL} / \mathrm{min}$ and $I_{W . E}=-15 \mathrm{~mA}$. Comparing these results with those obtained in optimized conditions on the RVC 500 ppi cathode exploited in potentiostatic conditions with simple air injection in the catholyte flow, substantial improvements of the $\left[\mathrm{H}_{2} \mathrm{O}_{2}\right]_{F}, C . E F_{\text {.I }}$ and $W_{S . I}$ values, of $82.5,70$ and $33 \%$, respectively, were recorded. Also, comparing the $E_{\text {W.E }}$ mean values $\left(E_{\text {W.E.M }}\right)$ evaluated in galvanostatic mode with the $E_{W . E}$ values imposed in potentiostatic mode, it is obviously that the use of the new aeration system induced a significant decrease of the 
electrolyte conductivity, determining important increases of the $E_{W . E . M}$ values. This phenomenon becomes more evident during the increase of the $Q_{\text {air }}$ values from 10 to $40 \mathrm{~mL} / \mathrm{min}$, but decreases in intensity for $Q_{a i r}=80 \mathrm{~m} / \mathrm{min}$ (see row 6 from table 3 ), indicating that an excessive aeration reduces the efficiency of the A.W.M., determining a poor emulsion stability and the formation of large air bubbles.

Concerning the optimization studies for the recycled GG cathode exploited in galvanostatic mode and using the original aeration system, by correlating the data from fig. 7.B and table 3 (last 6 rows), we concluded that the best EIEHPAP were obtained at $Q_{\text {air }}=10 \mathrm{~mL} / \mathrm{min}$ and $I_{\text {W.E. }}=-10 \mathrm{~mA}$. Comparing these results with those obtained in optimized conditions on the RVC 500 ppi cathode exploited in similar conditions, very promising values for the global EIEHPAP were obtained. Practically, using this extremely cheap cathodic material, even if the $\left[\mathrm{H}_{2} \mathrm{O}_{2}\right]_{F}$ and C.EF.I values decreased with $53 \%$ and $30 \%$, the $W_{S . I}$ presented an excellent value, of $5.38 \mathrm{kWh} / \mathrm{kg}$ of HP.

Finally, using the same experimental setup, optimization studies were performed in galvanostatic mode for the GB and GF cathodes, a comparison of the best intermediate and global EIEHPAP for all tested materials being presented in fig. 8 and the first 4 rows of the table 4, respectively. Supplementary, in the last lines of table 4 (from row 5 to end), several examples of EIEHPAP calculated based on literature data for similar electrodes and experimental conditions are presented. For a more eloquent comparison, the reported $I_{\text {W.E. }}$ values were replaced by the corresponding current densities $(j$ W.E. $)$ and a new efficiency indicator, extremely significant, was introduced, corresponding to the HP global generation rate (G.G.R.) and calculated as:

$$
\text { G.G.R. }=\frac{\left[\mathrm{H}_{2} \mathrm{O}_{2}\right]_{F} \cdot V_{C A T}}{S_{W . E .} \cdot t_{F}}\left(\mathrm{mg} \cdot \mathrm{s}^{-1} \mathrm{~cm}^{2}\right)
$$

where $S_{\text {W.E. }}$ represent the geometrical W.E. surface exposed towards the anode.

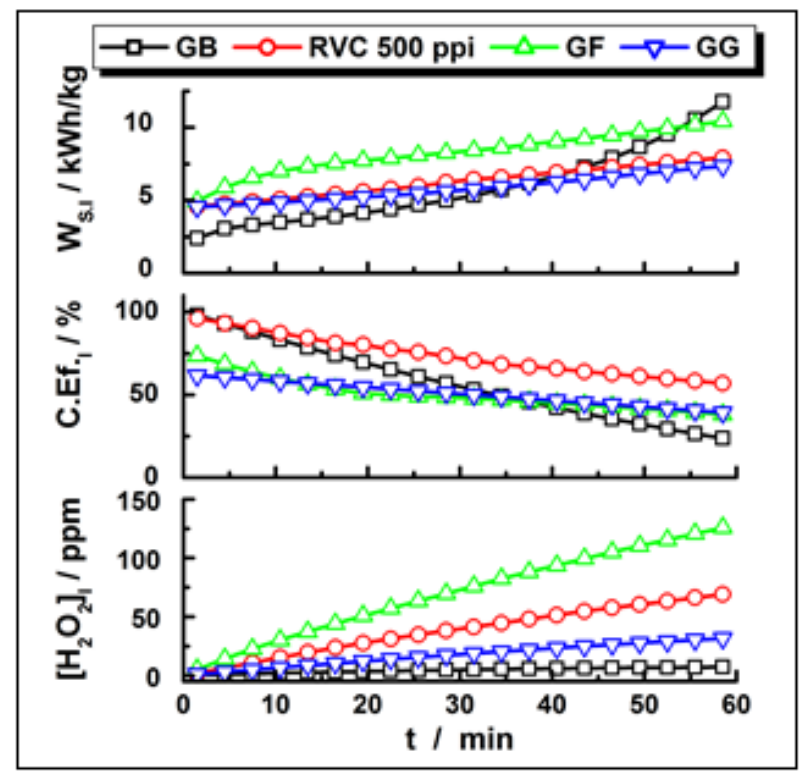

Fig. 8. Comparison between the intermediate EIEHPAP evaluated in galvanostatic mode, in optimized conditions, for the GB, GF, RVC 500 ppi and GG cathodes at $Q_{e l}=40 \mathrm{~mL} / \mathrm{min}$. 
Table 4

COMPARISON BETWEEN THE GLOBAL EIEHPAP EVALUATED IN GALVANOSTATIC MODE, IN OPTIMIZED CONDITIONS, FOR THE GB, GF, RVC 500 PPI AND GG CATHODES AT $Q_{E L}=40 \mathrm{ML} / \mathrm{MIN}$ AND COMPARISON WITH LITERATURE DATA

\begin{tabular}{|c|c|c|c|c|c|c|c|c|c|}
\hline No. & $\begin{array}{l}\text { Cathode } \\
\text { material }\end{array}$ & $\begin{array}{l}\text { Oxygen } \\
\text { supply }\end{array}$ & $\underset{\left(\mathrm{mA} / \mathrm{cm}^{2}\right)}{j w . z}$ & $\begin{array}{c}Q_{\text {air } / 02} \\
(\mathrm{~mL} / \mathrm{min})\end{array}$ & $\begin{array}{c}{\left[\mathrm{H}_{2} \mathrm{O}_{2}\right]_{\mathrm{F}}} \\
\text { (ppm) }\end{array}$ & $\begin{array}{l}\text { C.Ef.G } \\
(\%)\end{array}$ & $\begin{array}{c}W_{S . G} \\
(\mathrm{kWh} / \mathrm{kg})\end{array}$ & $\begin{array}{c}\text { G.G.R. } \\
\left(\mathrm{mg} \mathrm{s}^{-1} \mathrm{~cm}^{2}\right)\end{array}$ & Ref. \\
\hline 1 & $\mathrm{~GB}$ & \multirow{4}{*}{$\begin{array}{l}\mathrm{AICF}^{\mathrm{a}}+ \\
\mathrm{A} . \mathrm{W} . \mathrm{M}\end{array}$} & 0.20 & 10 & 7.2 & 56.76 & 4.94 & $2.08 \cdot 10^{-5}$ & \multirow{4}{*}{ This work } \\
\hline 2 & RVC500ppi & & 1.50 & 10 & 73.0 & 76.20 & 5.84 & $2.03 \cdot 10^{-4}$ & \\
\hline 3 & GF & & 4.00 & 40 & 128.1 & 50.11 & 7.99 & $3.56 \cdot 10^{-4}$ & \\
\hline 4 & GG & & 1.00 & 10 & 34.0 & 53.31 & 5.38 & $9.44 \cdot 10^{-5}$ & \\
\hline$\overline{5}$ & $\overline{\mathrm{GB}}$ & $\overline{\text { ASCC }^{b}}$ & 0.9 & 200 & 40.0 & 14.02 & N.A. & $2.12 \cdot 10^{-5}$ & [11] \\
\hline 6 & $\mathrm{~GB}$ & $\mathrm{OSCC}^{\mathrm{d}}$ & 0.9 & 200 & 160.0 & 56.06 & N.A. & $8.47 \cdot 10^{-5}$ & [11] \\
\hline 7 & RVC60ppi & OSCT & 13.6 & Sat. & 180.0 & 55.65 & 7.14 & $1.33 \cdot 10^{-3}$ & [16] \\
\hline 8 & RVC80ppi & OSCT & 12.3 & 6000 & 420.0 & 63.00 & 4.00 & $1.36 \cdot 10^{-3}$ & [31] \\
\hline 9 & RVC100ppi & $\overline{A S C C}$ & 1.4 & 200 & 250.0 & 52.56 & N.A. & $1.32 \cdot 10^{-4}$ & [11] \\
\hline 10 & RVC100ppi & OSCC & 2.0 & 200 & 475.0 & 71.33 & N.A. & $2.51 .10^{-4}$ & [11] \\
\hline 11 & GF & ATGF $^{2}$ & 3.1 & $0.7 \mathrm{bar}$ & 80.0 & 84.10 & 5.40 & $4.63 \cdot 10^{-4}$ & [34] \\
\hline 12 & GC3 pellets & ASCC & 3.8 & Sat. & 11.9 & 3.52 & N.A. & $2.38 \cdot 10^{-5}$ & [19] \\
\hline
\end{tabular}

By correlating the data from fig. 8 and table 4 , we concluded that GB induces the best (lowest) $W_{S . G}$ from all tested materials and experimental parameters, but, unfortunately, the lowest G.G.R. Our results, in accordance with other reported data (see lines 1 and 5 from table 4), indicate that enormous FPER are required for large scale industrial applications. The productivity can be increased up to 4 times (see line 6 from table 4) by using pure oxygen, but this approach raises the production costs.

Concerning the RVC 500 ppi cathode tested in galvanostatic mode, it determines the highest $C . E f . G$ value and a G.G.R. 10 times bigger comparing to the GB electrode, in accordance with other reported results for air or pure $\mathrm{O}_{2}$ sparging in the cathodic compartment of a divided tank reactor (see lines 2, 9 and 10 from table 4). As indicated in the lines 7 and 8 from table 4, the productivity of RVC cathodes in respect to the EHPA process can be increased up to 10 times by using a divided FPER and pure $\mathrm{O}_{2}$ sparging in the C.T., with the corresponding increase of the production costs. Moreover, the high fragility and price of the RCV materials hinder the industrial development, only laboratory scale experiments being reported.

For optimized conditions and identical $S_{W . E}$. value $\left(10 \mathrm{~cm}^{2}\right)$, GF cathode assures the highest productivity (maximal $\left[\mathrm{H}_{2} \mathrm{O}_{2}\right]_{F}$ and G.G.R. values), but the worst HPE efficiency (lowest C.Ef.G and highest $W_{S . G}$ values), a similar G.G.R. being reported only for a more complicated setup, based on the air injection through the GF cathode (see line 11 from table 4).

Finally, comparing the best results obtained for the recycled GG cathode with those evaluated for the other tested materials, we conclude that it present satisfactory and very promising performances, assuring a G.G.R. 2 times smaller and 5 times bigger in relation to the RVC and GB electrodes, respectively. Also, the obtained productivity is 4 times larger as that reported for a granular cathode from glassy carbon pellets (see line 12 from table 4). Starting from this encouraging results, further improvements of the HPE efficiency for the recycled GG cathode will be tested based on electrode geometry optimization, surface pre-treatment [7, 21, 24, 27], use of surfactants [31] or implementing programmable pulsed current $[40,41]$.

\section{Conclusions}

To the best of our knowledge, the recycled GG from spent $\mathrm{Zn}-\mathrm{C}$ batteries were for the first time proposed and tested as 3D cathode for HPE based on electrochemical ORR, their performances being 
compared to those of other commercial carbonaceous materials (GB, GF and RVC). For all tested electrodes, the best results were obtained in galvanostatic mode and using the original aerating system implemented, also, during the present work. In these conditions, based on $1 \mathrm{~h}$ optimization tests, we conclude that the most efficient material for EHPA was RVC of 500 ppi, $\left[\mathrm{H}_{2} \mathrm{O}_{2}\right]_{F}, C$.Ef.G and $W_{S . G}$ values of $71 \mathrm{ppm}, 74.1 \%$ and $6.1 \mathrm{kWh} / \mathrm{kg}$, respectively, being obtained.

Even if the use of the GB electrode determine the minimal $W_{S . G}$ (of $4.94 \mathrm{kWh} / \mathrm{kg}$ ), unfortunately, it induce the minimal G.G.R., of $2.08 \cdot 10^{-5} \mathrm{mg} \mathrm{s}^{-1} \mathrm{~cm}^{2}$. Similarly, the GF electrode leads to a maximal $\left[\mathrm{H}_{2} \mathrm{O}_{2}\right]_{F}$ values $(128.1 \mathrm{ppm})$, but to a minimal C.Ef.G values of $50 \%$.

For the GG cathode, very promising global efficiency indicators were evaluated $\left(\left[\mathrm{H}_{2} \mathrm{O}_{2}\right]_{\mathrm{F}}=34 \mathrm{ppm}\right.$, C.Ef.G $=53.3 \%$ and $W_{S . G}=5.4 \mathrm{kWh} / \mathrm{kg}$ ), suggesting that this extremely cheap material can be transformed, after a minimal treatment (washing. grinding and sieving), in a versatile 3D cathode for HPE. Moreover, improved results can be obtained by the optimization of other operational parameters (e.g. GG diameter, current profile, etc.) and GG pretreatment.

From another point of view, our studies revealed that the thickness of the 3D cathodes can plays an essential role when low conductivity electrolytes are used for HPE, too thick electrodes being able to induce highly nonuniform distribution of the potential and favoring the parasitic processes. Also, the aeration mode and air flow rate influence significantly the EHPA process efficiency, excessive sparging being able to reduce the HP accumulation rate.

\section{References}

1.PLATON, N., SIMINICEANU, I., NISTOR, I.D., MIRON, N.D., SILION, M., JINESCU, C., HARROUNA, M., AZZOUZ, A., Rev. Chim., 64, (12), 2013, p. 1459.

2.ORBECI, C., PASCU, L.F., MODROGAN, C., Rev. Chim., 66, (4), 2015, p. 482.

3.ORBECI, C., MODROGAN, C., DANCILA, A. M., Rev. Chim., 67, (1), 2016, p. 166.

4.SIRÉS, I., BRILlAS, E., OTURAN, M.A., RODRIGO, M.A., PANIZZA, M., Environ. Sci. Pollut. Res., 21, 2014, p. 8336.

5.MARTINEZ-HUITLE, C.A., RODRIGO, M.A., SIRES, I., SCIALDONE, O., Chem. Rev., 115, no. 24, 2015, p. 13362.

6.PLAKAS, K.V., SKLARI, S.D., YIANKAKIS, D.A., SIDEROPOULOS, G.T., ZASPALIS, V.T., KARABELAS, A.J., Water Res., 91, 2016, p. 183.

7.MIAO, J., ZHU, H., TANG, Y., CHEN, Y., WAN, P., Chem. Eng. J., 250, 2014, p. 312.

8.MOREIRA, F.C., BOAVENTURA, R.A.R., BRILLAS, E., VILAR, V.J.P., Appl. Catal. B: Env., 202, 2017, p. 217.

9.SIMINICEANU, I., ALEXANDRU, C.I., ERIC BRILLAS, E., Rev. Chim. (Bucharest), 57, nr.11, 2006, p. 1082.

10.ZHANG, H., WAN, X., LI, G., ZHANG, F., Electrochim. Acta, 250, 2017, p.42.

11.PETRUCCI, E., DA POZZO, A., DI PALMA, L., Chem. Eng. J., 283, 2016, p. 750.

12.BRILLAS, E., Chem. Rev., 109, 2009, p. 6570.

13.PERALTA, E.M., NATIVIDAD, R., ROA G., MARIN, R., ROMERO, R., PAVON T., Sustain. Environ. Res., 23, no.4, 2013, p. 259.

14.MOHAMMADI, H., BINA, B., EBRAHIMI, A., Process. Saf. Environ. Prot., 117, 2018, p. 200.

15.WALSH, F.C., ARENAS, L.F., PONCE DE LEÓN, C., READE, G.W., WHYTE, I., MELLOR, B.G., Electrochim. Acta, 215, 2016, p. 566.

16.RAMÍREZ-PEREDA, B., ALVAREZ-GALLEGOS, A., RANGEL-PERAZA, J.G., RANGELPERAZA, J.G., BUSTOS-TERRONES, Y.A., J. Environ. Manag., 213, 2018, p. 279.

17.LI, J., AI, Z., ZHANG, L., J. Hazard. Mater., 164, 2009, p. 18.

18.LIU, D., ZHANG, H., WEI, Y., LIU, B., LIN, Y., LI, G., ZHANG, F., Chemosphere, 209, 2018, p. 998.

19.CHMAYSSEM, A., TAHA, S., HAUCHARD, D., Electrochim. Acta, 225, 2017, p. 435. 
20.KHATAEE, A., SAJJADI, S., POURAN, S.R., HASANZADEH, A., JOO, S.W., Electrochim. Acta, 244, 2017, p. 38.

21.LE, H.T.X., BECHELANY, M., CRETIN, M., Carbon, 122, 2017, p. 564.

22.MA, L., ZHOU, M., REN, G., YANG, W., LIANG, L., Electrochim. Acta, 200, 2016, p. 222.

23.ZHOU, L., HU, Z., ZHANG, C., BI, Z., JIN, T., ZHOU, M., Sep. Purif. Technol., 111, 2013, p. 131.

24.WANG, Y., LIU, Y., WANG, K., SONG, S., TSIAKARAS, P., LIU, H., Appl. Catal. B: Environ., 165, 2015, p. 360.

25.DIVYAPRIYA, G., NAMBI, I., SENTHILNATHAN, J., Chemosphere, 209, 2018, p. 113.

26.LI, Q., BATCHELOR-MCAULEY, C., LAWRENCE, N. S., HARTSHORNE, R. S., JONES, C. J. V., COMPTON, R. G., J. Solid State Electrochem., 18, 2013, p. 1215.

27.ZHOU, L., ZHOU, M., ZHANG, C., JIANG, Y., BI, Z., YANG, J., Chem. Eng. J., 233, 2013, p. 185.

28.YU, X., ZHOU, M., REN, G., MA, L., Chem. Eng. J., 263, 2015, p. 92.

29.ZHANG, C., REN, G., WANG, W., YU, X., YU, F., ZHANG, Q., ZHOU, M., Sep. Purif. Technol., 208, 2018, p. 76.

30.ALVAREZ-GALLEGOS, A., PLETCHER, D., Electrochim. Acta, 44, 1998, p. 853.

31.DE OLIVEIRA, B., BERTAZZOLI, R., J. Electroanal. Chem., 611, 2007, p. 126.

32.BADELlinO, C., RODRIGUES, C.A., BERTAZZOLI, R., J. Appl. Electrochem., 37, 2007, p. 451.

33.FIGUEROA, S., VAZQUEZ, L., ALVAREZ-GALLEGOS, A., Water Res., 43, 2009, p. 283.

34.PEREZ, T., CORIA, G., SIRES, I., NAVA, J.L., URIBE, A.R., J. Electroanal. Chem., 812, 2018, p. 54.

35.PÉREZ, J.F., LlANOS, J., SAEZ, C., LOPEZ, C., CANIZARES, P., RODRIGO, M.A., Electrochem. Commun., 71, 2016, p. 65.

36.PEREZ, J.F., LLANOS, J., SAEZ, C., LOPEZ, C., CANIZARES, P., RODRIGO, M.A., Electrochim. Acta, 246, 2017, p. 466.

37.PEREZ, J.F., LLANOS, J., SAEZ, C., LOPEZ, C., CANIZARES, P., RODRIGO, M.A., Sep. Purif. Technol., 208, 2019, p. 123.

38.PEREZ, J.F., LLANOS, J., SAEZ, C., LOPEZ, C., CANIZARES, P., RODRIGO, M.A., Electrochem. Commun., 89, 2018, p. 19.

39.ZHOU, W., RAJIC, L., ZHAO, Y., GAO, J., QIN, Y., ALSHAWABKEH, N.A., Electrochim. Acta, 277, 2018, p. 185.

40.MĂRINCEAN, A.D., DORNEANU, S.A., ILEA, P., Studia UBB - Chemia, LXI, nr. 3(1), 2016, p. 155.

41.ZHOU, W., GAO, J., DING, Y., ZHAO, H., MENG, X., WANG, Y., KOU, K., XU, Y., WU, S., QIN, Chem. Eng. J., 338, 2018, p. 709.

42.LING, T., BIN HUANG, B., ZHAO, M., YAN, Q., SHEN, W., Bioresour. Technol., 203, 2016, p. 89.

43.LI, X., ANGELIDAKI, I., ZHANG, Y., J. Power Sources, 341, 2017, p. 357.

44.WANG, C.T., HU, J.L., CHOU, W.L., KUO, Y.M., J. Hazard. Mater., 152, 2008, p. 601.

45.ZHANG, H., LI, Y., ZHANG, H., LI, G., ZHANG, F., Sci. Rep., 9:1817, 2019, p. 1.

$\overline{\text { Manuscript received: } 14.08 .2019}$ 